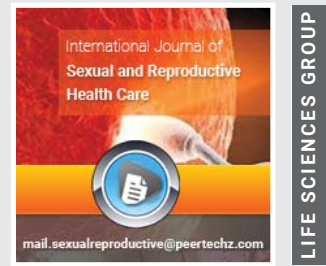

\title{
Second-birth fertility desire and social factors in married women in Zhejiang province, China: A cross-sectional study
}

Received: 12 March, 2020

Accepted: 22 April, 2020

Published: 24 April, 2020

*Corresponding author: Haiyan Xing, Department of Nursing, School of Medicine Shaoxing University, 900 Chengnan Avenue Shaoxing,312000, Zhejiang Province, China, E-mail: petrelx99@163.com

Keywords: Socioeconomic status; Second-birth fertility desire

https://www.peertechz.com

\section{Check for updates}

\author{
Chunyan Zhou' ${ }^{1}$, Haiyan Xing ${ }^{2 \star}$ and Wei YU ${ }^{3}$ \\ 'Department of Clinical Medicine, School of Medicine,Shaoxing University, 900 Chengnan Avenue \\ Shaoxing,312000, Zhejiang Province, China \\ ${ }^{2}$ Department of Nursing, School of Medicine Shaoxing University, 900 Chengnan Avenue \\ Shaoxing,312000, Zhejiang Province, China \\ ${ }^{3}$ Institute of Epidemiology, Shaoxing Keqiao District Center for Disease Control and Prevention, \\ Zhejiang Province, China
}

\begin{abstract}
Background: After the universal two-child policy in China, the Second-Birth Fertility Desire (SBFD) has aroused widespread concern. There have been some research on SBFD, however, current reports on social factors and SBFD are not detailed. The objective was to investigate the impact of social factors on SBFD and to explore correlation between them.

Methods: By stratified sampling, 436 married women who had one child from urban area in Zhejiang province had completed the questionnaires in 2017. Multiple Correspondence Analysis (MCA) was performed to clarify the relationship between SBFD and socioeconomic factors such as Socioeconomic Status (SES).

Results: The results showed that the determinants of second-birth fertility desire varyed across parities: SES, age and Couple from One-Child Families (CFOCF). MCA showed that couples both from one-child families or whose SES were "Mid-High" were inclined to have a second child. The "Not sure" second-birth fertility desire was related with one of the couple from one-child families and "Middle" SES. Married women whose SES were "Low" or "Mid-Low" or 40+ years old were not prone to have a second child.
\end{abstract}

Conclusion: Second-birth fertility desire was related with social factors, including SES, age and CFOCF. Government should be focus on people with middle and above socioeconomic status, couples who have at least one spouse from one-child family and people under 40 to improve the total fertility rate of urban dwellers.

\section{Abbreviations}

SBFD: Second-Birth Fertility Desire; SES: Socioeconomic Status; CFOCF: Couple from One-Child Families; MCA: Multiple Correspondence Analysis; CA: Correspondence Analysis; TFR: Total Fertility Rate

\section{Plain English summary}

People are producing fewer and fewer children and the Total Fertility Rate (TFR) are declining in the world especially developed countries, which has contributed to a reduction in the population sizes. China's one-child family policy has had a great effect on the lives of population for nearly 40 years. However new problems arise as rapidly ageing and high sex ratio according to the development of economy and policy implementation. So selective two-child policy and universal two-child policy have been introduced successive. In this paper, the Second-Birth Fertility Desire (SBFD) was explored among 436 married women who had one child living in Zhejiang province, a urban district in eastern China. Overall, the study found that three factors (Socioeconomic Status (SES), Couple from One-Child Families (CFOCF) and age) be associated with SBFD. The couples both from one-child families or whose SES 
were "Mid-High" were inclined to have a second child. However women whose SES were "Low" or "Mid-Low" or 40+ years old were not prone to have a second child. The findings suggest a need to target those who are middle and above socioeconomic status, couples who have at least one spouse from one-child family and people under 40 years old in order to raise secondchild fertility levels in urban population.

\section{Background}

The one-child family policy was introduced in 1978 to slow population growth and improve economic level and living standards. Despite the policy's success, massive changes have taken place in the social economy during the past 35 years. Problems such as very low fertility, a rapidly ageing population and the high sex ratio arose [1-2]. Fertility dropped below the replacement level in the early 1990 s and has been increasingly lower [3]. The Total Fertility Rate (TFR) was 1.6-1.8, and lower than the world standard 2.1. In 2017, the number of neonates decreased by 630 thousand compared with the same period in 2016 all around the country [4].The proportion of population at the age of 60 and age of 65 and above reached $15.53 \%$ and $10.06 \%$ in 2014 [5].The sex ratio was 118 , rising to 135 in some rural areas. The sex ratio at birth started to rise about 25 years ago, peaking at 121 in 2005 [6].The high sex ratio at birth has a close relationship with the decline of the Total Fertility Rate(TFR), and both have negative correlation, the reversal time was around 1980 [7]. In order to reduce risks and negative effects, China started to adjust the onechild policy to improve the total fertility rate and to alleviate the degree of population aging [5]. Selective two-child policy was performed on November 2013, which indicated that either the husband or the wife from a single-child family could have a second child. However, the eligible fertility rate was much lower than expected after one and a half years. The policy that a couple could have two children(universal two-child policy) was implemented on January 2016 [5].

Although the government encourages the second child fertility recently, fertility desire and behavior are closed with factors such as age, socioeconomic status, housing, medical services, working status, education level, income, gender of first-birth, raising costs and gender inequality in housework [8-10]. Socioeconomic Status (SES) was one of the main socioeconomic factors, as assessed by income, educational achievement, job and so on. Some studies showed that SES's widely accepted definition was identified and classified into different levels: 3 ranks (low, middle and high) or 5 ranks(low, mid-low, middle, mid-high and high) [11-14]. On the basis of socioeconomic status scale proposed by an American sociologist Duncan, Li Qiang conducted localization research in China, and established a SES scale of Chinese large city. The SES scale included income, occupation and educational level [15]. Different SES possessed unequal social resources, and affected fertility desire.

\section{Methods}

\section{Subjects and procedure}

Data were obtained from cross-sectional survey in 2017. The target population comprised married women aged from 20 to 50 who had one child and were from urban areas in Zhejiang province, randomly selected by stratified sampling technique. At first, three stratifications were divided by economic level in Zhejiang province (3,4,4 cities respectively). Wenzhou, Shaoxing and Huzhou were chosen to survey. In each city, three communities were sampled randomly. About 30 percent of this target population for study sample according to the community registration information. We got 436 valid questionnaires with the response rate of $99.1 \%$.

\section{Social class}

Social classes were determined by income, education and employment. The item was rated 1 (low) to 7 (high) in the three variables respectively. The score of social class was the total score of income, education and employment. So that a high score indicated a higher social class.

\section{Statistical analysis}

Statistical analyses performed by SPSS version 18.0 software, included the $\chi^{2}$ test and multiple correspondence analysis(MCA). If there were significant difference between second-birth fertility desire and socioeconomic factors $(P<0.05)$ based on $\chi^{2}$ test, MCA was performed to assess the relationship of related variables. Correspondence analysis(CA) is a way to scale jointly a matrix of non-negative data to represent objects described by rows or columns as points in a lowdimensional space and decompose a measure of association. MCA is the multivariate version of CA used to analyze data tables containing three or more variables(features). The results of MCA are presented in the form of graphs $[16,17]$. MCA was performed based on optimal scaling in SPSS software.

\section{Results}

\section{Socioeconomic score}

In accordance with Qiang Li's socioeconomic score, the monthly household income per capita in the original scale was revised according to the income level of urban residents in Zhejiang Province in 2016. The specific scores are shown in Table 1. Urban women were divided into five groups according to the total score of the three indicators(education, income and job) (Table 2 for details).

\section{Second-birth fertility desire}

No significant difference in the gender of first-birth or the number of abortions was found. However,the second child fertility desire was significantly different in the factors of age, CFOCF and SES( $\mathrm{P}<0.05$, Table 3$)$. The second child fertility desires of different ages were: age 20-34(21.5\%), 35-39 (19.2\%) and 40+ years (8.8\%). The factor CFOCF was associated with second-child fertility desire: both (22.4\%), one $(17.9 \%)$ and none $(15.7 \%)$. On the other hand, people of different socioeconomic status haddifferent second-child fertility desires: low(11.1\%), mid-low (20.0\%), middle (14.4\%), mid-high (22.4\%) and high (35.7\%).

There were good discriminations in dimension1 and dimension2 in three variables(couple from one-child families, 
second child fertility desire and SES). Good discrimination was also found in gender in dimension1 (Figure 1).

The MCA dimensions explained almost $74.5 \%$ of total variance. Dimension 1 contributed $60.1 \%$ of the total inertia and dimension 2 contributed $39.9 \%$. In the MCA plot, four variables

Table1: Indicators of socioeconomic score in urban women.

\begin{tabular}{|c|c|c|c|c|c|}
\hline Education & Score & $\begin{array}{c}\text { Monthly } \\
\text { household } \\
\text { income per } \\
\text { capita(yuan) }\end{array}$ & Score & Job & Score \\
\hline$<$ Primary school & 1 & $<520$ & 1 & $\begin{array}{c}\text { Temporary workers / } \\
\text { unemployed }\end{array}$ & 1 \\
\hline Primary school & 2 & $521 \sim 1560$ & 2 & Manual worker & 2 \\
\hline Middle school & 3 & $1561 \sim 2600$ & 3 & Skilled worker & 3 \\
\hline High school & 4 & $2601 \sim 5200$ & 4 & General office staff & 4 \\
\hline $\begin{array}{l}\text { Technical School/ } \\
\text { Professional } \\
\text { School }\end{array}$ & 5 & $5201 \sim 7800$ & 5 & $\begin{array}{l}\text { General managers/ } \\
\text { general professional } \\
\text { technicians }\end{array}$ & 5 \\
\hline College/ University & 6 & $7801 \sim 10400$ & 6 & $\begin{array}{l}\text { Middle management } \\
\text { staff/middle professional } \\
\text { technicians }\end{array}$ & 6 \\
\hline$\geq$ Postgraduate & 7 & $\geq 10401$ & 7 & $\begin{array}{l}\text { Senior management/ } \\
\text { senior professional } \\
\text { technicians }\end{array}$ & 7 \\
\hline
\end{tabular}

Table 2: Socioeconomic score in urban women.

\begin{tabular}{|c|c|c|c|}
\hline Social class & Range of score & Frequency & Percent(\%) \\
\hline High & $18 \sim 21$ & 14 & 3.2 \\
\hline Mid-High & $15 \sim 17$ & 76 & 17.4 \\
\hline Middle & $12 \sim 14$ & 181 & 41.5 \\
\hline Mid-Low & $9 \sim 11$ & 120 & 27.5 \\
\hline Low & $3 \sim 8$ & 45 & 10.3 \\
\hline Total & $/$ & 436 & 100.0 \\
\hline
\end{tabular}

Table 3: Second-birth fertility desire(SBFD).

\begin{tabular}{|c|c|c|c|c|}
\hline \multirow{2}{*}{ Classify } & \multicolumn{2}{|c|}{ Intention to have another child (\%) } & \multirow{2}{*}{ P value } \\
\hline & Have intention & Not sure & Do not have intention & \\
\hline$<35$ & & & & \\
\hline $35 \sim 39$ & $19(19.2)$ & $35(35.4)$ & $45(45.5)$ & \\
\hline $40+$ & $10(8.8)$ & $29(25.4)$ & $75(65.8)$ & \\
\hline Gender of first-birth & & & \\
\hline boy & $40(16.0)$ & $101(40.4)$ & $109(43.6)$ & \multirow{2}{*}{0.243} \\
\hline girl & $37(19.9)$ & $82(44.1)$ & $67(36.0)$ & \\
\hline Couple from one-child families(CFOCF) & & \\
\hline Both & $19(22.4)$ & $38(44.7)$ & $28(32.9)$ & \\
\hline One & $24(17.9)$ & $73(54.5)$ & $37(27.6)$ & \\
\hline None & $34(15.7)$ & $72(33.2)$ & $111(51.2)$ & \\
\hline SES & & & & \\
\hline Low & $5(11.1)$ & $15(33.3)$ & $25(55.6)$ & \\
\hline Mid-Low & $24(20.0)$ & $41(34.2)$ & $55(45.8)$ & \\
\hline Middle & $26(14.4)$ & $91(50.3)$ & $64(35.4)$ & \\
\hline Mid-High & $17(22.4)$ & $30(39.5)$ & $29(38.2)$ & \\
\hline High & $5(35.7)$ & $6(42.9)$ & $3(21.4)$ & \\
\hline Number of abortions & & & \\
\hline 0 & $43(16.7)$ & $106(41.2)$ & $108(42.0)$ & \\
\hline 1 & $24(19.7)$ & $52(42.6)$ & $46(37.7)$ & \\
\hline$\geq 2$ & $10(17.5)$ & $25(43.9)$ & $22(38.6)$ & \\
\hline
\end{tabular}

were divided into four quadrants to show the association of the categories. The points SBFD "Have intention", CFOCF "Both" and SES"Mid-High" were closer and distributed in the first quadrant, which showed that couples both from one-child families and with Mid-High SES were inclined to have a second child. There were relationships among the points SBFD"Not sure", CFOCF "One" and SES= "Middle" in the fourth quadrant. The SBFD"Do not have intention" was related to SES"Low", "Mid-Low" and 40+ years old in the second quadrant (Figure 2).

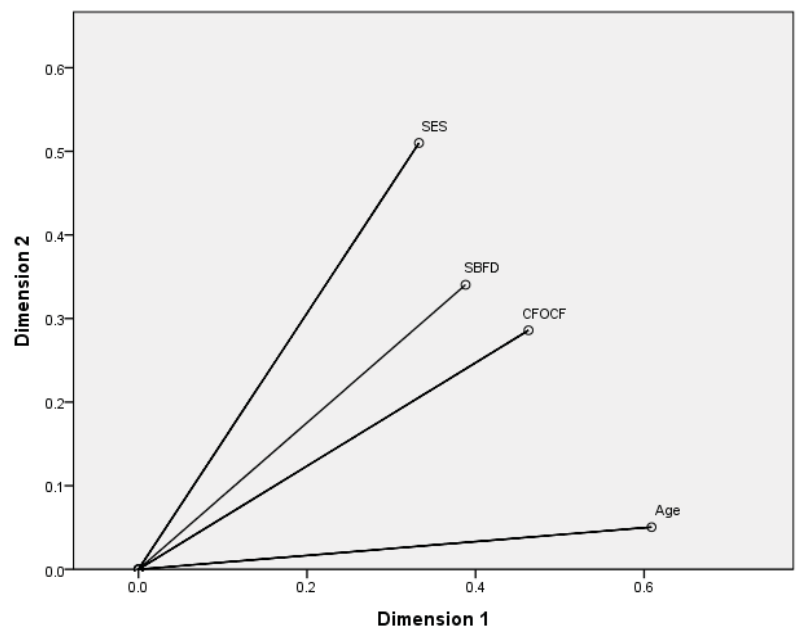

Figure 1: Discrimination measures of second-birth fertility desire and socioeconomic factors.

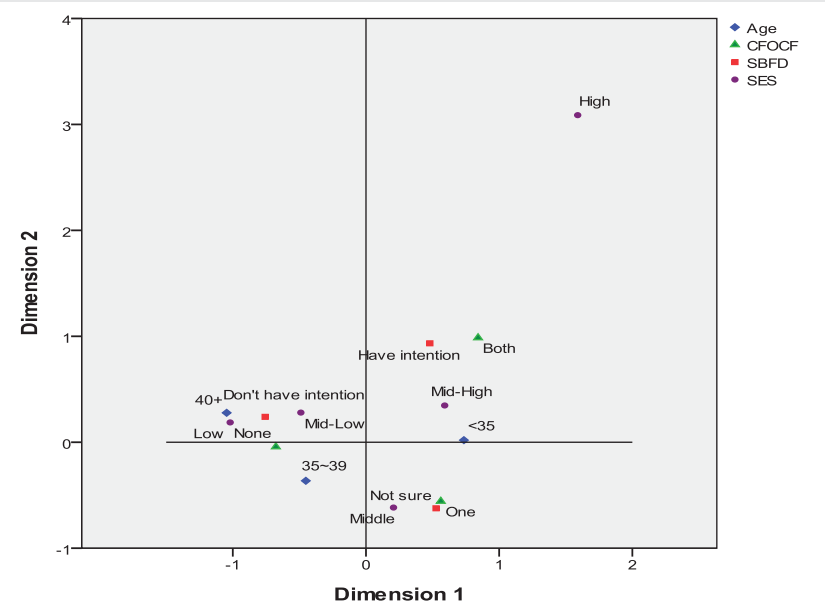

Figure 2: Multiple correspondence analysis of second-birth fertility desire and socioeconomic factors.

\section{Discussion}

Correspondence analysis provides a means of displaying or summarizing a set of data with categorical variables in twodimensional graphical form [18]. Multiple correspondence Analysis is to analyze the correlation of a set of attribute variables. In a lower dimensional space, the proportional structure of each element in the row and column is represented in the lower dimensional space.MCA is a widely used technique to analyze categorical data and aims to reduce large sets of

Citation: Zhou C, Xing H, YU W (2020) Second-birth fertility desire and social factors in married women in Zhejiang province, China: A cross-sectional study. Int $J$ Sex Reprod Health Care 3(1): 012-016. DOI: https://dx.doi.org/10.17352/ijsrhc.000010 
variables into smaller sets of components that summarize the information contained in the data [19]. MCA has been widely used in different fields and disciplines [20,21], it can serve to analyze real problems in a large variety of different fields, social surveys, psychometry, marketing and also to further develop the methodology to produce research papers [22]. In this study, MCA based on optimal scaling was used to study the correlation between socioeconomic factors and second-birth fertility desire.

MCA showed that couples both from one-child families and with "Mid-High" SES were inclined to have a second child. Couples both from one-child families had a higher SBFD , which was consistent with the results of other research [23,24]. People from one-child families grew up in a lonely environment and were less likely to be accompanied by brothers or sisters. On the other hand, they also took greater pension pressure from the future " $4: 1$ " family structure ( 4 old people and 1 child). So they were often inclined to have two or more children.

The study showed that women of "Mid-High" SES were inclined to have a second child. On the contrary, women of "Low"and" Mid-Low" SES had lower intentions. With the improvement of socioeconomic status, second- birth fertility desire was on the rise. Some research suggested that secondbirth fertility desire was largely affected by family income and economic conditions [23,25-26]. People with stable high income tended to have a second child [23]. Almost all people who didn't want a second child mentioned economic pressure. Families in the middle of or even below the social economy were busy to make a living every day and didn't have superfluous energy and time to take care of one more child. Due to higher and higher costs of raising children, parents paid more attention to living and education quality rather than the number of children and "High" SES. Though "High"SES was also in the first quadrant, it was far away from the point "Have intention" SBFD .so their relationship was not so close, which confused us. In this study, except for income, SES also included education and job. High-income and well-educated women preferto be successful at work, perhaps second-child will affect their career pursuits. However, people with "MidHigh" and "High" SES often possess more social resources and better education to provide their children with good living environment, so government should encourage them to have second child in order to improve the overall quality of the next generation.

Age is also one of the most important factors for most women to make the second-child birth plan. Age of women has a certain effect on the second-child fertility desire [27]. "Intergenerational difference" makes different age groups have different fertility desires. In this study, married women aged $40+$ were not inclined to have a second -child. Due to various burdens produced by the first child and greater risk of fertility as the age increases, fertility will weaken. Some studies confirmed that the older a woman is, the less willing to have a second child, especially over 35 years old $[28,29]$.

In this study, gender preference was not a factor to secondchild fertility desire among married women. The percent of intention for the second child was $17.9 \%$ (first child was a boy) vs. $18.3 \%$ (first child was a girl), and there was no significant difference $\left(\chi^{2}=0.314, p=0.855\right)$. Compared to mother, father preferred to fertility boys [9].

In the last four decades, the one-child family policy and social economic development have jointly promoted the decline of China's fertility level [30]. At the same time, the increase in the cost of raising children has reduced fertility. Reduced fertility, improved living conditions, and increased life expectancy in recent years will lead to the rapid increase of elderly population and the rapid decrease of human workforce in the following decades. This phenomenon will turn into a serious social challenge [31]. Government should be focus on people with middle and above socioeconomic status, couples who have at least one spouse from one-child family and people under 40to improve the total fertility rate of urban dwellers. On the surface, the problem of birth is a family problem, and its essence is a major basic problem in the operation of the social and economic system. Population policies will have a major impact on a country's economic development, social stability and improvement of people's living standards. The universal two-child policy not only plays a key role in relieve the aging of society, but also is necessary to solve the problem of low fertility in the long run [32]. The second child can make the family more harmonious and lead a better life, it also helps the children to cultivate the spirit of solidarity and mutual assistance, learn to share and take responsibility, optimistic and cheerful disposition and so on.

The universal two-child policy is the intermediate link between fertility desire and fertility behavior. Fertility behavior has a strong population selectivity and uncertainty [33]. So whether the fertility desire can be transformed into actual fertility behavior depends largely on the birth plan and other factors.

\section{Limitations}

The study only sampled three cities in this province, although it had a large sample size, the results were not applicable to all aspects and could not be generalized to whole married women in Chinese cities. It was difficult to establish cause and effect relationship between second-birth fertility desire and socioeconomic factors based on a cross sectional study. Family planning was couple based and fertility did not depend on women's desire only. Lots of factors other than individual issues were involved. Other factors such as health status, husband's age and age gap, husband or whole family's second-birth fertility desire and the health of first-child that were known as influencing factors on second-birth fertility desire, were not measured in this research.

\section{Conclusion}

Fertility desire can be influenced by a number of factors that operate at the social and individual levels. Second-birth fertility desire was related with social factors, including SES, age and CFOCF. Government should be focus on people with middle and above socioeconomic status, couples who have at least one spouse from one-child family and people under 40 to improve the total fertility rate of urban dwellers 


\section{Declarations}

\section{Ethics Approval and Consent to Participate}

The study was approved by the ethics committee of the Shaoxing Universtiy Medical College. The respondents were anonymous, voluntary and consent for participation.

\section{Availability of data and material}

Please contact author for data requests.

\section{Author's contributions}

CZ carried out literature review and drafted the manuscript. HX designed and directed the study, analyzed data and revised the manuscript. WY took the responsibility of data collection. All authors read and approved the final manuscript.

\section{Acknowledgments}

We are grateful to the Research Assistants who conducted data collection and the married women who participated in the study.

\section{References}

1. Basten S, Jiang Q (2015) Fertility in China: An uncertain future. Popul Stud(Camb) 69: S97-105. Link: https://bit.ly/2wYM2ca

2. Hesketh T, Lu L, Xing ZW (2005) The effect of China's one-child family policy after 25 years. N Engl J Med 353: 1171-1176. Link: https://bit.ly/2VXsBt0

3. Zhai ZW, Zhang XL, Jin YA (2014) Demographic consequences of an immediate transition to a universal two-child policy. Population Research 38 3-17 Link: https://bit.ly/2S37QdY

4. Representative's suggestion (2018) Reducing or exempting personal income tax for second-born households to increase fertility intention. Link: https://bit.ly/2VxePhm

5. Zeng Y, Zhang XJ, Liu L (2017) From "selective two-child policy" to universal two-child policy: will the payment crisis of China's pension system be solved? China Finance and Economic Review 5: 14. Link: https://bit.ly/2Y2VeaG

6. Zhou XD, Li L, Yan Z, Hesketh T (2013) High sex ratio as a correlate of depression in Chinese men. J Affect Disord 144: 79-86. Link: https://bit.ly/351S4oW

7. Liang HY, Chao N (2018) Recognition on the Imbalance of Sex Ratio at Birth in China. Human Resources Development of Chin 35: 112-121.

8. Xiao-Tian F, Poston DL, Xiao-Tao W (2014) China's One-child Policy and the Changing Family. J Comp Fam Stud 45: 17-29. Link: https://bit.ly/3cUC23h

9. Ma L, Fang XM, Lei Z, Cai XC (2016) Does Only Child's Gender Affect the Fertility Desire of Only-child Parents to Bear a Second Child? -A Study from Chinese General Social Survey (CGSS). Population Journal 38: 17-26.

10. Chen MN, Yip PSF (2017) The Discrepancy Between Ideal and Actual Parity in Hong Kong: Fertility Desire, Intention and Behavior. Popul Res Policy Rev 36: 583-605. Link: https://bit.ly/2xU56sF

11. Akhbar-Williams T (2010) Class structure. In Encyclopedia of African American popular culture (ed. JC Smith) Westport, CT: Greenwood 1: 320-323.

12. Brown DF (2009) Social class and status. In Concise encyclopedia of pragmatics (ed. JL Mey), 953.Amsterdam, The Netherlands: Elsevier.
13. Gilbert $D$ (2002) The American class structure: in an age of growing inequality Beverley Hills, CA: Pine Forge Press.

14. Stiglitz J (2013) The Price of Inequality. New Perspectives Quarterly 30: 52-53.

15. Li Q (2010) Social stratification in contemporary China: Measurement and analysis. Beijing: Beijing Normal University Publishing House

16. Greenacre MJ (1984) Theory and application of correspondence analysis Academic Press, New York. Link: https://bit.ly/3axD3fR

17. Suchanek M, Robouch P, Aregbe Y, Herrero A, Taylor P (2007) The use of multiple correspondence analysis for the evaluation of inter-laboratory comparisons. Accred Qual Assur 12: 399-403. Link: https://bit.ly/3azEqKQ

18. Uceda J, Carmona L, Muñoz A, Marenco JL (2012) The reason to stop infliximab is clearlyrelated to the existence of new alternatives:a correspondence analysis of biologics, reasonsto stop, and time periods. Journal of Translational Medicine 10: 28. Link: https://bit.ly/3aviZuJ

19. Mori Y, Kuroda M, Makino N (2016) Multiple Correspondence Analysis. Nonlinear Principal Component Analysis and Its Applications. Springe Singapore 91-116. Link: https://bit.ly/355CXef

20. Brunette $M$, Bourke R, Hanewinkel M, Yousefpour R (2018) Adaptation to Climate Change in Forestry: A Multiple Correspondence Analysis (MCA) Forests 9: 20. Link: https://bit.ly/2yBjkyL

21. Martin-Mazé M (2018) Multiple Correspondence Analysis in International Relations. Resources and Applied Methods in International Relations. Link: https://bit.ly/2VWDbQD

22. Murtagh F (2006) Multiple correspondence analysis and related methods Chapman Hall. CRC 275-277.

23. Wang DX, Wang ZM (2017) An investigation on the influencing factors of second child fertility willingness in Dalian. Chin J Postgrad Med 40: 879-883. Link: https://bit.ly/2Y059xG

24. Zhaomin M, Ruijun W (2011) The discrepancy between fertility intentions and behavior in different families. E-Journal Of China Urban Studies 6: 167-173.

25. Tian LF, Rong TH, Zhang XY, Sun $Q$, Zhang JC, et al (2017) A study on the influencing factors of rural couples' fertility desire under the "universal twochild policy" -- Taking Tianjin as an example. Population and Development 23 . 104-112.

26. Han L, Tian LP (2016) Fertility Intention and Fertility Behavior under the Universal Two-child Policy-Analysis of Survey Data in Xiangtan City in 2014 Journal of Xiangtan University (Philosophy and Social Sciences) 40: 51-56.

27. Asfaw HM, Gashe FE (2014) Fertility intentions among HIV positive women aged18-49 years in Addis Ababa Ethiopia: a cross sectional study. Reprod Health 11: 36. Link: https://bit.ly/3aAoR5V

28. Tian RJ (2016) Will women's family strengthen the low fertility level? An empirical study on family power and reproductive decision making). Population and Society 32: 93-102.

29. Zhang $X Q$, Huang $\mathrm{CH}$, Zhang Q, Chen SS, Fang QP (2016) Comparison and Enlightenment of family child bearing intention between "Selective two-child policy" and "universal two-child policy". Population Research 40: 69-70.

30. Chen W (2008) Lowest-low fertility in China. Population Research 32: 31-34.

31. Kalantari S, Abbaszadeh M, Amin MF, Rakeei BN (2010) The sociological study of attitude to child bearing and it's some related factors, case study: married youth in Tabriz City 21: 83-104. Link: https://bit.ly/3eOwsRp

32. Shi PP, Li T (2017) Thinking about the second child's child bearing desire and parenting pressure under the background of population aging. An Hui Wen Xue 115-116.

33. Wang GL, Zhang LP (2017) Second-birth fertility desire under low fertility leve in China. Youth Exploration 5-14.

Copyright: @ 2020 Zhou C, et al. This is an open-access article distributed under the terms of the Creative Commons Attribution License, which permits unrestricted use, distribution, and reproduction in any medium, provided the original author and source are credited.

Citation: Zhou C, Xing H, YU W (2020) Second-birth fertility desire and social factors in married women in Zhejiang province, China: A cross-sectional study. Int $J$ Sex Reprod Health Care 3(1): 012-016. DOI: https://dx.doi.org/10.17352/ijsrhc.000010 